\title{
Over-expression of the IGII leading to altered shoot-branching development related to MAX pathway in Arabidopsis
}

\author{
Indeok Hwang • Soo Young Kim • Cheol Soo Kim • \\ Yoonkyung Park · Giri Raj Tripathi $\cdot$ Seong-Ki Kim • \\ Hyeonsook Cheong
}

Received: 20 October 2009/Accepted: 28 April 2010/Published online: 15 May 2010

(C) The Author(s) 2010. This article is published with open access at Springerlink.com

\begin{abstract}
Shoot branching and growth are controlled by phytohormones such as auxin and other components in Arabidopsis. We identified a mutant (igil) showing decreased height and bunchy branching patterns. The phenotypes reverted to the wild type in response to RNA interference with the IGII gene. Histochemical analysis by GUS assay revealed tissue-specific gene expression in the anther and showed that the expression levels of the IGII gene in apical parts, including flowers, were higher than in other parts of the plants. The auxin biosynthesis component gene, CYP79B2, was up-regulated in igil mutants and the
\end{abstract}

Electronic supplementary material The online version of this article (doi:10.1007/s11103-010-9645-0) contains supplementary material, which is available to authorized users.

I. Hwang $\cdot$ Y. Park $\cdot$ H. Cheong $(\bowtie)$

Department of Biotechnology and BK21 Research Team for

Protein Activity Control, Chosun University, Gwangju 501-759,

Korea

e-mail: hscheong@chosun.ac.kr

S. Y. Kim

Department of Molecular Biotechnology and Kumho Life Science Laboratory, College of Agriculture and Life Sciences, Chonnam National University, Gwangju 500-757, Korea

C. S. Kim

Department of Plant Biotechnology and Agricultural Plant Stress Research Center, Chonnam National University,

Gwangju 500-757, Korea

G. R. Tripathi

Central Department of Biotechnology, Tribhuvan University, Katgmandu, Nepal

S.-K. Kim

Department of Life Science, Chung-Ang University, Seoul 156-756, Korea
IGII gene was down-regulated by IAA treatment. These results indicated that there is an interplay regulation between IGI1 and phytohormone auxin. Moreover, the expression of the auxin-related shoot branching regulation genes, MAX3 and MAX4, was down-regulated in igil mutants. Taken together, these results indicate that the overexpression of the IGII influenced MAX pathway in the shoot branching regulation.

Keywords Shoot branching - IGI1 - MAX pathway

\section{Introduction}

Evaluation of branching patterns is important in plant architecture. Although many studies have been conducted to evaluate hormones and genetic controls, the mechanisms responsible for the control of axillary branching are still not fully understood. It has been well-established that auxin is involved in shoot branching and apical dominance. For example, it is known that the outgrowth of lateral buds is suppressed in decapitated plants that are subjected to auxin treatment (Thimann and Skoog 1933). It is also well known that other factors such as cytokinins regulate shoot branching and apical dominance as second messengers ( $\mathrm{Li}$ et al. 1995; Tantikanjana et al. 2001). Dun et al. (2006) explained branching control using three hypotheses such as the classical hypothesis, auxin transport hypothesis and bud transition hypothesis, each of which involved in the plant hormone auxin. The classical hypothesis suggests that shoot branching is regulated by auxin via secondary messengers such as cytokinin (Sachs and Thimann 1967; Bangerth 1994; Li et al. 1995). The auxin transport hypothesis suggests that shoot branching is controlled by auxin movement in the auxin transport stream as opposed 
to the actual auxin level. In this process, the auxin derived in the shoot tip of the main inflorescence is transported basipetally into the axillary bud, which results in complete inhibition of the axillary bud outgrowth (Morris 1977; Li and Bangerth 1999). The bud transition hypothesis suggests that the bud enters different developmental stages that have varying degrees of sensitivity or responses to longdistance signals, including auxin (Stafstrom and Sussex 1992; Shimizu-Sato and Mori 2001; Morris et al. 2005).

Recently, long-distance signaling components were identified such as More Axillary Growth (MAX) from Arabidopsis, Ramosus (RMS) from Pea, and decreased apical dominance (DAD) from Petunia. MAX4 is an ortholog of the DADl gene in Petunia and the RMS1 gene in Pea (Sorefan et al. 2003; Snowden et al. 2005). MAX4 is homologous with carotenoid cleavage dioxygenases required to produce a mobile branch-inhibiting signal downstream of auxin (Sorefan et al. 2003). MAX3 encodes a plastidic dioxygenase that can cleave multiple carotenoids and is required for the synthesis of a novel carotenoid-derived long-range signal that regulates shoot branching (Booker et al. 2004). MAX2 is an F-box, leucine-rich repeat-containing member of the SCF family of ubiquitin ligases (Stirnberg et al. 2002). MAX1 controls vegetative axillary bud outgrowth via the regulation of the flavonoid pathway, which acts the downstream of MAX3/4 to produce a carotenoid-derived branch-inhibiting hormone, and encodes a member of the CYP450 family, CYP711A1. Analysis of the maxl-max4 mutants demonstrates that branching is regulated by at least one carotenoid-derived hormone and four MAX genes acting in a single pathway, with MAX1, MAX3, and MAX4 acting in hormone synthesis, and MAX2 acting in hormone perception (Booker et al. 2005). Another branching signal component, branched 1 (BRC1), is involved in the MAX pathway, where it encodes a TCP transcription factor in Arabidopsis that is closely related to the teosinte branched $1(t b l)$ of maize. $B R C l$ expression was localized in developing buds and down-regulated in branch outgrowth. RNAi (RNA interference) and a double mutant experiment indicated that the $B R C$ gene prevents the rosette branch outgrowth downstream of the MAX pathway, and the pathway including BRC component required auxin induced apical dominance (Aguilar-Martínez et al. 2007). Schachtschabel and Boland (2009) proposed that shoot branching hormones known as strigolactones (previously known as carotenoid-derived hormones) inhibited shoot branching (Umehara et al. 2008; Gomez-Roldan et al. 2008; Sergeant et al. 2009). The bud outgrowth and tillering were inhibited by GR24, strigolactone analog, treated in pea and rice. In arabidopsis, the increased branching number in the $\max 3$ and max4 mutants also decreased with GR24 treatments (Umehara et al. 2008; Brewer et al. 2009).
Here we describe a mutant that has an abnormal shoot branching pattern, decreased plant height and increased branching. The mutant phenotypes were attenuated by RNA interference with the IGII (Inflorescence Growth Inhibitor 1) gene. The MAX3 and MAX4 genes were downregulated in igil mutants. These results indicate that the mutant phenotypes are caused by the overexpression of the IGII gene related to MAX pathway. We propose a new component for axillary branching control.

\section{Results}

Increased shoot branching and decreased plant height in isolated mutants

Genetic approaches in mutant screening are important for evaluating gene function in plants. We obtained morphologically distinguishable mutants from activation tagged lines and chose a mutant that exhibited a number of phenotypes including smaller silique, semisterility, bunchy stems and shortened inflorescence. Among 1638 progenies in the F2 generation produced by self-fertilization of the F1 generation of the original mutant, the following phenotypes were observed in three classes with a ratio of approximately $1: 2: 1$; sterile and severely defective; many branches similar to the original mutant; normal and similar to the wild-type Columbia-0 (Col-0) (Fig. 1b). To confirm single T-DNA insertion, back-crossing with Col-0 to the original mutant was conducted. In the F1 generation, the progeny showed a segregation ratio of approximately 1:1 (survival plants: dead plants) when cultivated in medium containing basta. All survived plants showed phenotypes similar to the original mutant in soil. In progenies in which seven plants survived in the F1 generation, the progeny showed a segregation ratio of approximately 3: 1 (basta resistant: basta sensitive) (Table 1). The viable plants also segregated among severely defective phenotypes and phenotypes that resembled the original mutant at a ratio of approximately 1:2 when grown in soil. These results indicate that the original mutant had a single T-DNA insertion and was a heterozygous plant. Three phenotypic classes in the next generation of the original mutant corresponded to plants containing a homozygous mutation, a heterozygous mutation, or no mutation. Upon self pollination, plants that had a Col-0 phenotype produced only Col-0 progeny, whereas all original mutants segregated into the three phenotypic classes. When the heterozygous mutant was evaluated, the phenotype of young seedlings was similar to that of the wild type, while the homozygous mutant had curled and smaller leaves (Fig. 1a).

The sterile homozygous mutant had no inflorescence and an abnormal flower organ after the plants began to 

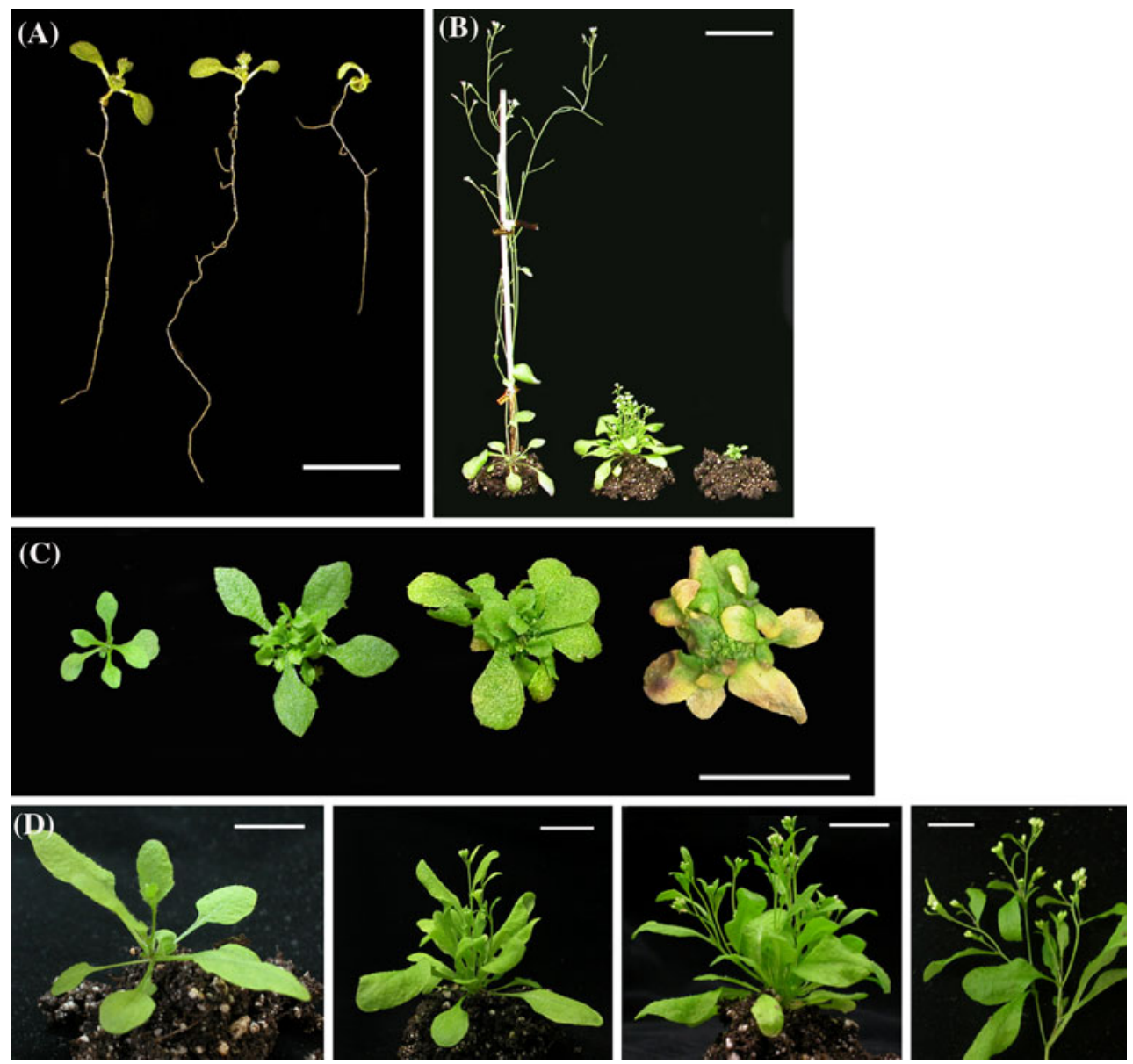

Fig. 1 Morphology of mutants. a Phenotype of 10-day-old plants. From left to right, Col-0, heterozygous and homozygous mutant. Scale bar: $5 \mathrm{~cm}$. b Phenotype of 25-day-old plants. From left to right, Col-0, heterozygous and homozygous mutant. Decreased plant height and increased axillary branches are displayed in the heterozygous mutant. The homozygous mutant displays no inflorescence and abnormal flowers. Scale bar: $5 \mathrm{~cm}$. c The phenotype of the homozygous mutant during different growth stages. From left to right, 10, 20, 30, and 40day-old plants. Scale bar: $2 \mathrm{~cm}$. d The phenotype of the heterozygous mutant during different growth stages. Each panel shows a 20-day-old plant (first panel), 25-day-old plant (second panel), 30-day-old plant (third panel), and multiple axillary inflorescences of the 35-day-old plant (fourth panel). Scale bar $2 \mathrm{~cm}$ for the first to third panel and $1 \mathrm{~cm}$ for the fourth panel

Table 1 Segregation ratio of the igil progeny

\begin{tabular}{llll}
\hline Plant/cross & Number of plants & & Sterile plants \\
\cline { 2 - 4 } & Original mutant phenotype & 119 & Dead plants \\
\hline The original mutant/self & 226 & 0 & 31 \\
The original mutant $\times$ wild type & 38 & 910 & 941 \\
F1 & 1638 & & \\
F2 (7 plants) & &
\end{tabular}

Screened mutants did not have single T-DNA. After the mutant was back-crossed with Col-0, genotyping PCR was performed in the F2 generation to identify single T-DNA insertion lines. After fixing the original mutant, which contained a single T-DNA insertion, the mutant was back-crossed with Col-0 to determine if it was a single T-DNA insertion line or not. After seeding the heterozygous mutant (expected) in 1/2MS medium containing basta $20 \mathrm{mg} / \mathrm{L}$, the plants were counted

flower (Fig. 1c). The heterozygous mutant plants produced primary inflorescence with reduced internode elongation and the growth of primary inflorescence stopped during the emergence of the secondary inflorescences. The number of inflorescences that develop from the rosette leaves in Col-0 is usually in the range of $1-5$, and fewer than 10 include the inflorescence of cauline leaves. Conversely, heterozygous mutant plants continue to produce axillary inflorescences 
from the axils of both rosette and cauline leaves. Consequently, heterozygous mutants have dramatically increased the numbers of axillary branches (Fig. 1d).

The phenotypes of igil mutants were caused by IGII gene overexpression

To determine the T-DNA locus of the mutants, we extracted genomic DNA from the heterozygous mutant and then performed thermal asymmetric interlaced-PCR (TAIL-PCR) using arbitrary genomic primers and T-DNA specific primers. Segregation ratio analysis, TAIL-PCR walking and genotyping PCR results indicated a single T-DNA insertion 200 bp upstream of the At1g23540 coding region in the BAC F5O8 (Fig. 2a). We referred to the
Atlg23540 gene as IGI1 (Inflorescence Growth Inhibitor 1) and the mutation as igil/IGII for the heterozygous and igil/igil for the homozygous mutant. After determining the T-DNA insertion site by the sequencing of TAIL-PCR products containing the T-DNA/plant genomic DNA junction, genotyping PCR was conducted to determine if the assayed plant was a wild type, homozygous mutant or heterozygous mutant (data not shown). After the T-DNA position and direction were determined, the expression levels of nearby genes flanking the T-DNA were evaluated by quantitative Real time PCR. The expression level of the AtIg23540 IGII gene was approximately 1,000-3,000 fold higher in the igi/igi mutant and 500-1,000 fold higher in the igil/IGII mutant when compared to the wild type. The expression of other neighboring genes also slightly increased
Fig. 2 Identification of IGII. a T-DNA position in the igil mutants. BAC F5O8 clone is shown. There is a T-DNA insertion $200 \mathrm{bp}$ upstream of the At 1 g23540 gene coding region. b The expression level of neighboring genes near the T-DNA. The real time PCR results show that the At 1223540 gene transcript was dramatically increased in igil mutants. Actin was used for normalization and the error bars indicate the standard deviation. c Phenotype of the igil/igil-RNAi mutant. Col-0, igil/IGI1, igil/igil, and igil/igil-RNAi (left to right). d Results of real-time PCR of the igil/igil-RNAi mutant. Actin was used for normalization and the error bars indicate the standard deviation
(A)

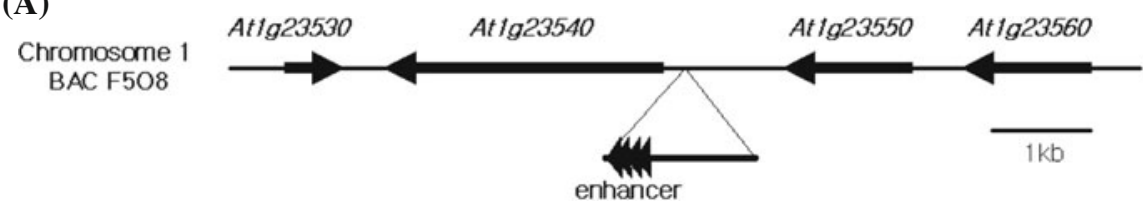

(B)
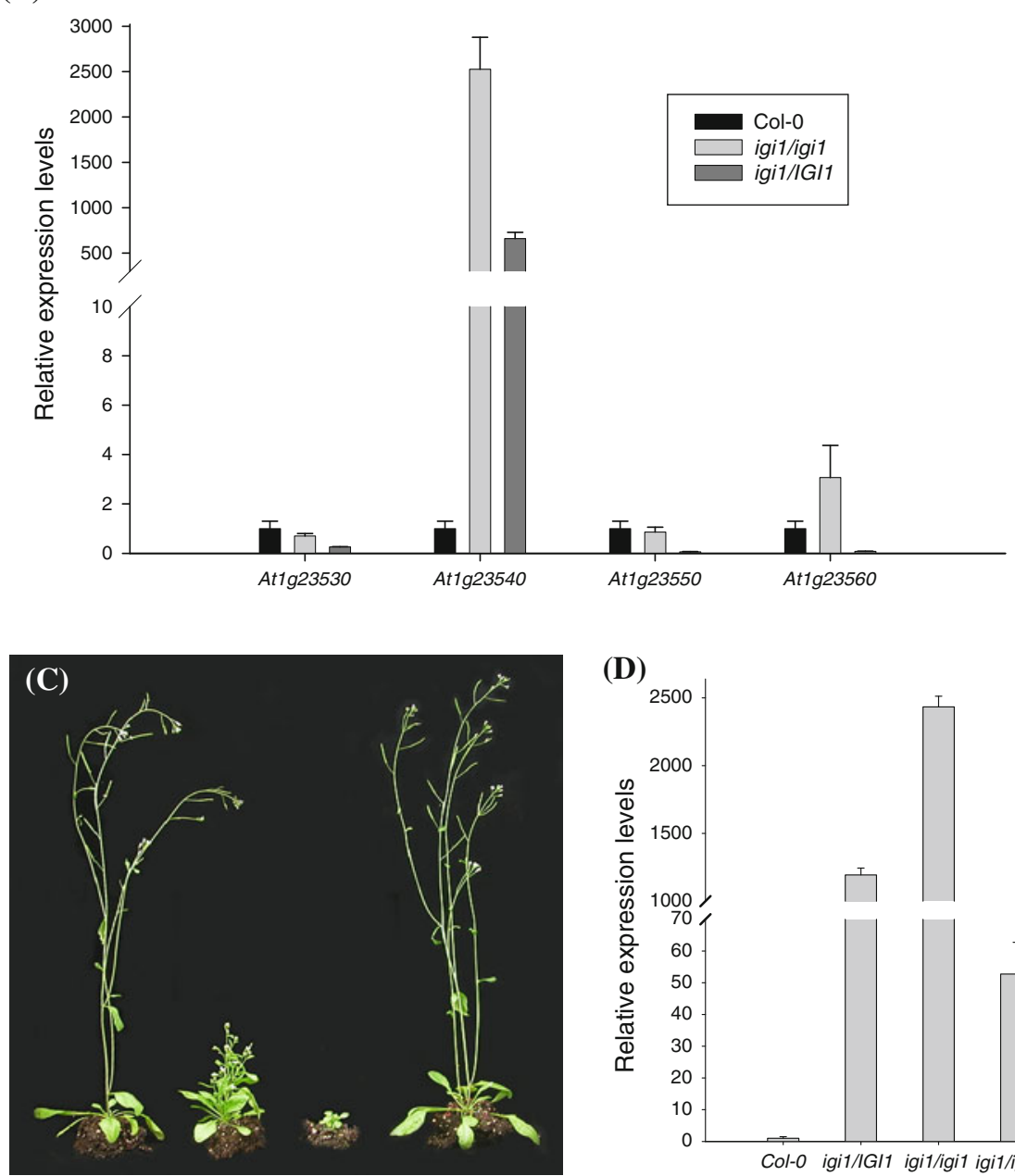

(D)

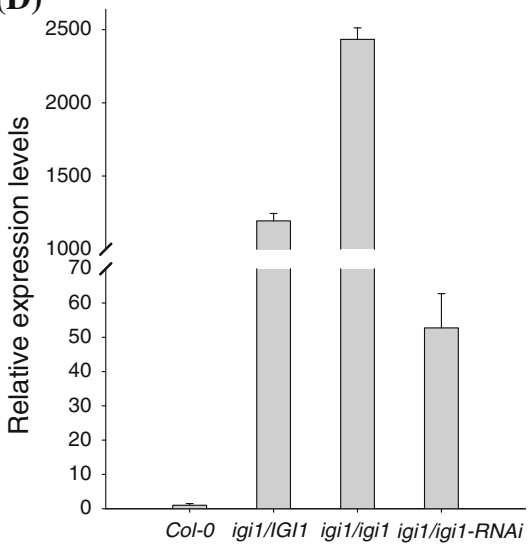


in the igil/igil mutant, but not in the igil/IGIl mutant (Fig. 2b). These results suggest that the IGII gene overexpression caused the igil mutant phenotypes.

To rescue the igil mutant phenotypes, a recapitulation construct was generated. Recapitulation vector pMN20 including the four enhancers was used (Weigel et al. 2000) for this experiment. The $3.3 \mathrm{~kb}$ IGII gene containing its own promoter was amplified by the PCR amplification of the Col-0 genomic DNA and then cloned into pMN20 vector. After cloning, the construct was transformed into the Col-0 plants. The T3 homozygous lines were generated from $\mathrm{T} 2$ individuals carrying a single insertion, which was identified by a $3: 1$ segregation ratio on 1/2MS medium containing kanamycin. The mRNA levels of the recapitulation mutants were analyzed by quantitative real-time PCR. IGII recapitulation lines \#1 (IGII-RC\#I) and IGII$R C \# 5$ showed high and moderate expression levels, respectively, when compared to the other recapitulation lines; therefore, these lines were selected. The expression levels of the IGII gene were lower in IGI-RC\#I and IGI$R C \# 5$ when compared to the igil mutants (Supplemental Fig. 1). Unexpectedly, we did not observe the same phenotypes produced by the igil mutants in the population of recapitulation mutants. The IGI-RC\#5 mutant had the same phenotype as Col-0. However, IGI-RC\#1 showed phenotypes somewhat similar to those of the igil/IGII mutant. Additionally, the number of inflorescences was significantly higher and the plant height was reduced in the IGIRC\#1 mutant (Supplemental Fig. 1c). These findings indicate that the IGI-RC\#I mutant could not recapitulate the igil mutant phenotypes completely, possibly because of lower expression levels in the recapitulation mutants.

We attempted to revert the phenotype of igil plants by reducing the mRNA levels using RNA interference (RNAi). To select the mutant, a segregation test in medium supplemented with hygromycin for the RNAi single locus and genotyping PCR for the igil locus in the F2 generation were performed (data not shown). IGII expression levels efficiently decreased in the RNAi transformed mutant, igil/ igil-RNAi, which had a phenotype similar to that of Col-0 (Fig. 2c, d). The phenotypes reverted when the mRNA levels were reduced, suggesting that the over-expression of the IGII gene caused the phenotypes of igil mutants such as sterility, lack of inflorescence and seeds, and abnormal flower organs in the igil/igil mutant and dramatically increased axillary branching in the igil/IGII mutant.

The IGII gene is strongly expressed in the anther

To evaluate the expression pattern of the IGII gene, we developed IGII promoter-GUS reporter construct (IGI1::GUS) for the histochemical GUS reporter assay. GUS expression was detected at low levels in only the hair zone of the primary root and not detected in other portions of the 5-day-old seedlings (Fig. 3a). In the 10-day-old seedlings, the expression was stronger in the 5-day-old seedlings than in the hair zone (Fig. 3b). GUS expression was also observed in only the flower parts when the plants were about to bolt (about 20 days after planting) (data not shown). In the 33-day-old plants, the expression was strong in the anthers and weak in the upper stem and immature siliques (Fig. 3c). GUS expression was found to be tissuespecific, being most strongly expressed in the anther. To confirm the expression pattern of the IGII gene, the expression levels were examined in different tissues by quantitative real time PCR. The expression levels in the flower part were much higher than in other parts such as the rosette and cauline leaves and the stems (Fig. 3d).

IGI1 is down-regulated by treatment of IAA

Auxin and cytokinin are important phytohormones for regulating the branching patterns (Ward and Leyser 2004). To analyze the relationship between hormones such as auxin and cytokinins and IGI1, we tested the transcription patterns of the genes enchanced or decreased by auxin treatment and cytokinin response genes.

The levels of cytokinin response genes such as ARR4 and $A R R 5$ were unchanged in the mutants (Supplemental Fig. 2a-d). In cytokinin sensitivity test conducted using a callus induction assay, the igil/igil and igil/IGII mutants also responded normally to cytokinin (Supplemental Fig. 3e). For the callus induction assay, plant hypocotyls grown in dim light for 15 days were excised with scissors and cultured for 20 days in 1/2MS.1S supplemented with $50 \mathrm{nM}$ 2,4-D and varying concentrations of kinetin (Higuchi et al. 2004).

The transcription patterns of the genes enhanced or decreased by auxin treatment differed slightly between 10-day-old plants (Supplemental Fig. 3), seedlings, 25day-old plants (Fig. 4) and those in the bolting stage. The expression level of the auxin biosynthetic component, CYP79B2, was significantly higher in the bolting stage, but CYP79B3 slightly increased in the 25-day-old mutants. Zhao et al. (2002) reported that IAA inducible genes such as IAA5 increased in response to $C Y P 79 B 2$ overexpression. However, with the exception of PIN1, there was no detectable variation in the transcript levels of the auxinregulated genes, IAA5, DFL1, LAX1, LAX3, ARF5, PID, and ATRl, in the igil mutants (Okushima et al. 2005). PIN1 expression levels decreased in the 25-day-old mutants.

To determine if the transcription of the IGII gene is affected by auxin and cytokinin, we analyzed the dosedependent expression patterns of the $I G I I$ gene after hormone treatment. Untreated 7-day old Col-0 seedlings were 
Fig. 3 Expression pattern of the IGII gene. a-c The expression pattern was detected using a GUS reporter gene under control of the $I G I I$ gene promoter. a-b. Histochemical staining of GUS activity in 5- (a) and 10-day-old (b) seedlings. Expression was detected only in the root hair. c Histochemical staining of GUS activity in each part of a 33-day-old plant. The pictures show the cauline inflorescence inflorescence, flower, and anther (left to right). GUS expression was weakly detected in the upper stem and immature siliques and strongly detected in the anther of the flowers. d The relative expression levels of the IGII gene in different tissues. The flower part has a higher expression level than the other parts. Actin was used for normalization and the error bars indicate the standard deviation and leaf, apical part of main
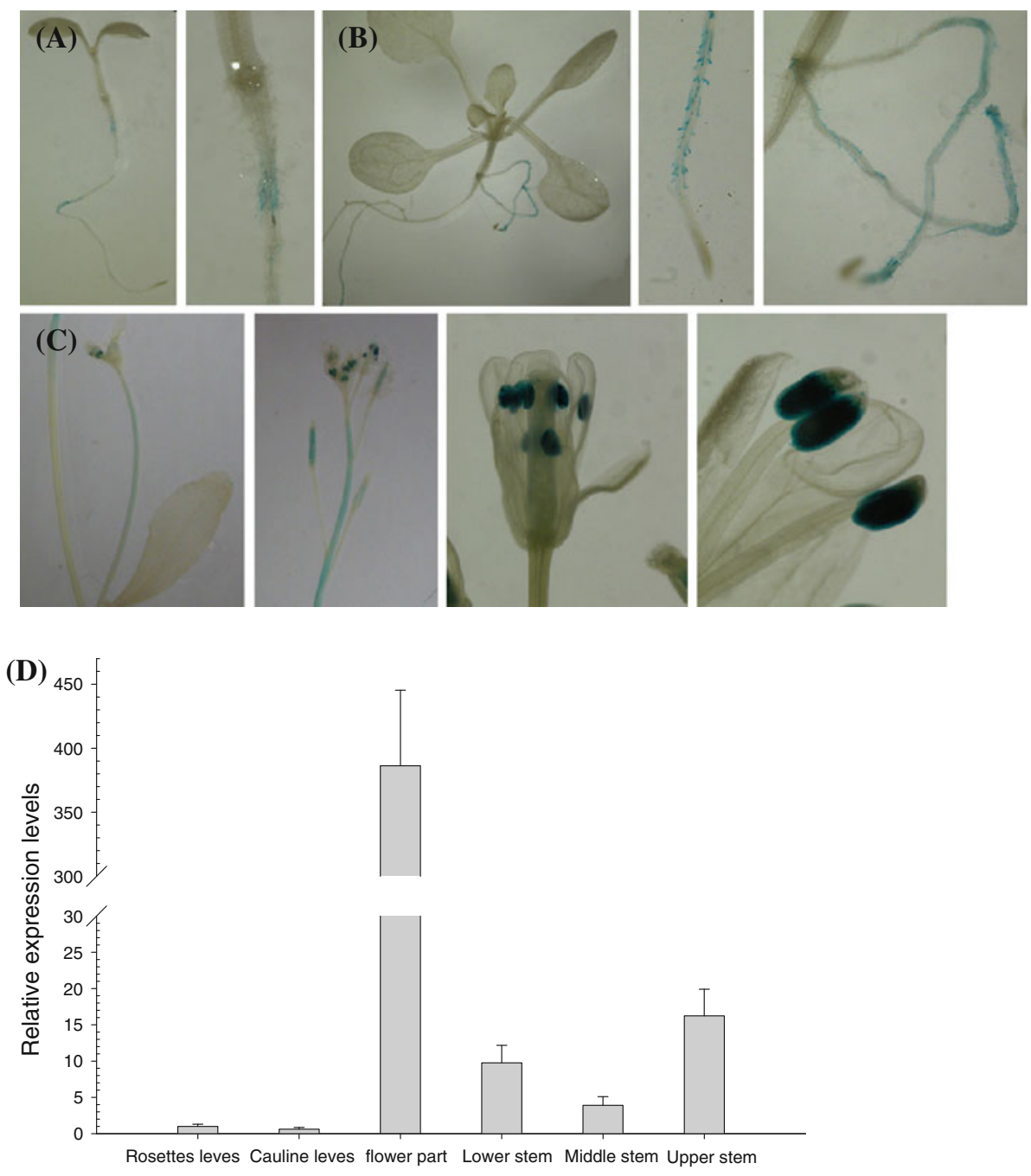

transferred to IAA and BAP treated medium, after which the seedlings were used to test the hormone response within $3 \mathrm{~h}$ of treatment. The IAA5, CYP79B2, and ARR4 genes were used to verify the accuracy of the experimental method. The expression of IAA5 increased in response to IAA treatment, while $A R R 4$ was up-regulated by BAP treatment. The auxin biosynthesis component $C Y P 79 B 2$ was down-regulated by IAA treatment. The expression of IGII was unchanged in response to BAP treatment; however, IGII was down-regulated by exogenous IAA (Fig. 5).

MAX3 and MAX4 are down-regulated in igil mutants

Because the auxin efflux carrier, PIN1, and auxin biosynthesis gene, CYP79B2 and CYP79B3, showed altered expression levels in igil mutants (Fig. 4c), it is possible that the transcription levels of genes related to the MAX pathway were changed (Bennett et al. 2006). Therefore, MAX and BRC expression were analyzed in igil mutants to determine if the expression of the genes was related to axillary bud outgrowth or branching regulation (Lazar et al. 2006; Stirnberg et al. 2002; Booker et al. 2004; Sorefan et al. 2003; Aguilar-Martínez et al. 2007; Bainbridge et al. 2005). The expression of the MAX1, MAX2, MAX4, BRC1, and $B R C 2$ genes was unchanged in 10-day-old igil mutants when compared to the wild type plants; however, MAX3 was slightly down-regulated (Supplmental Fig. 4). In the 25-day-old igil mutants, the MAX3 and MAX4 genes were down-regulated (Fig. 6), suggesting that IGI1 influence the MAX pathway directly or indirectly in the branching control.

\section{IGI1 belong to PERK protein family}

The IGII gene consists of 8 exons with over 2,800 base pair (bp), and the predicted IGI1 protein contains 720 amino acid residues (Fig. 7a). Database searches indicated that IGI1 belong to a proline-rich extensin like receper kinase (PERK) family. Nakhamchik et al. (2004) classified Atlg23540 into AtPERK12. Arabidopsis PERK gene 

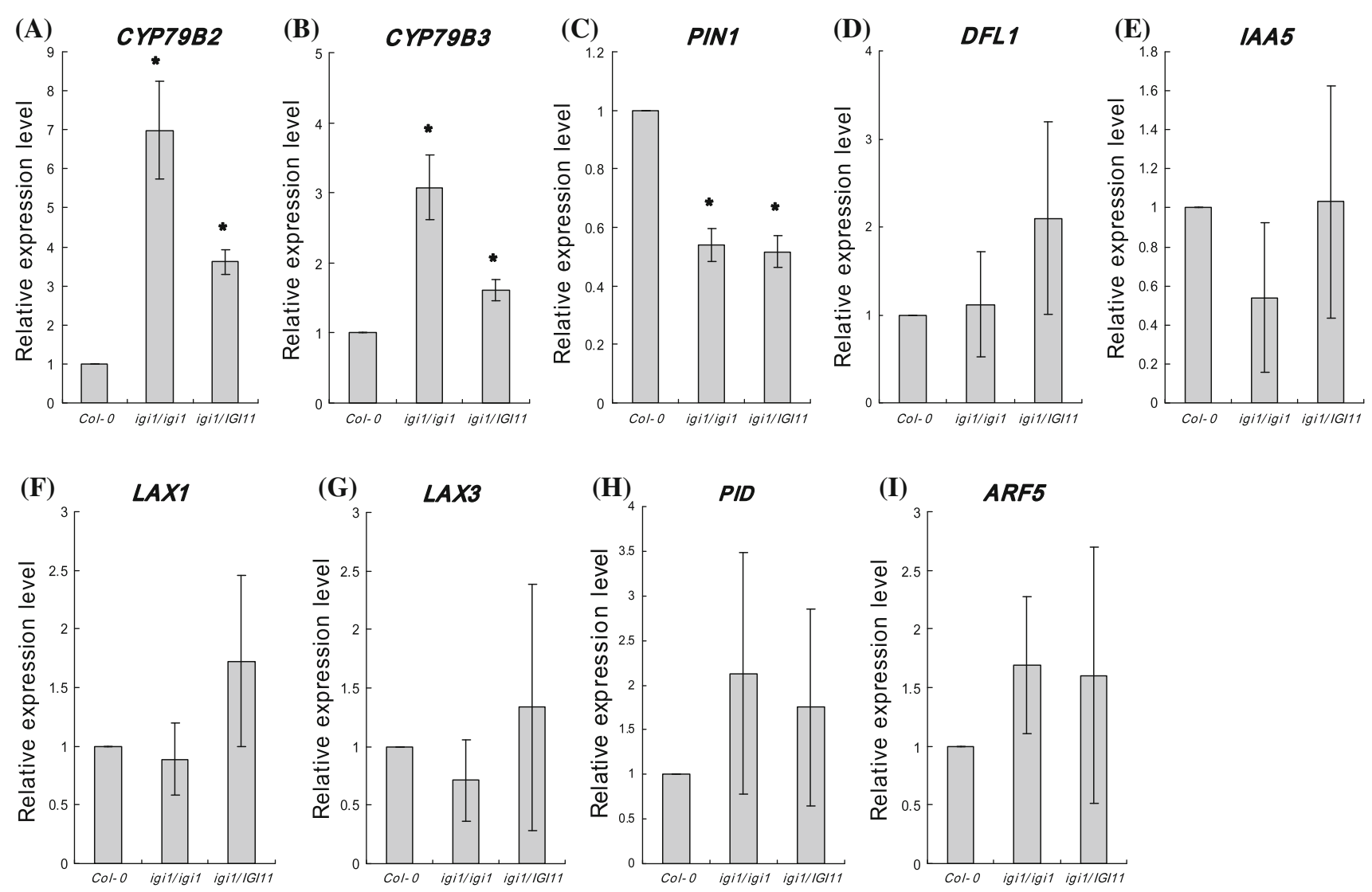

Fig. 4 Real-time PCR analysis related genes of the pytohormone auxin. The graph shows the relative expression levels of the auxin biosynthesis component (CYP79B2 and $C Y P 79 B 3)$, auxin efflux carrier (PIN1), DFL1, auxin induced gene (IAA5), LAX1, LAX3, PID and $A R F 5$. $C Y P 79 B 2$ and $C Y P 79 B 3$ were up-regulated and PIN1 was down-regulated in the igil mutants. PCR was conducted using the
cDNA of a 25-day-old plant as the template. The actin transcript levels were used for normalization. Error bars indicate the standard deviation. Results are the mean of at least three times. Asterisks indicate values significantly different from the wild type Col-0 $(P<0.05)$

CYP79B2, was up-regulated in igil mutants and the IGII gene was down-regulated by IAA treatment (Figs. 4, 5). In igil mutants, the expression of MAX3 and MAX4 was down-regulated (Fig. 6).

Auxin and cytokinin are important phytohormones involved in axillary branching and apical dominance (Cline 1997; Lincoln et al. 1990; Stirnberg et al. 1999). In the present study, a callus induction assay and transcript level test of the cytokinin response gene in igil mutants was conducted to investigate the relationship between cytokinin and IGI1. The cytokinin response of the igil mutants was similar to that of the wild type in the callus induction assay (Supplemental Fig. 2e). Cytokinin application to axillary buds and increased cytokinin levels induced bud outgrowth in Pisum sativum and Arabidopsis (Medford et al. 1989; Tantikanjana et al. 2001). Cytokinin also induced the cell division and the greening of hypocotyl-derived calli was partially inhibited in cytokinin receptor mutants (Higuchi et al. 2004). The transcript levels of the cytokinin response genes, $A R R 4$ and $A R R 5$, were similar in the wild type 

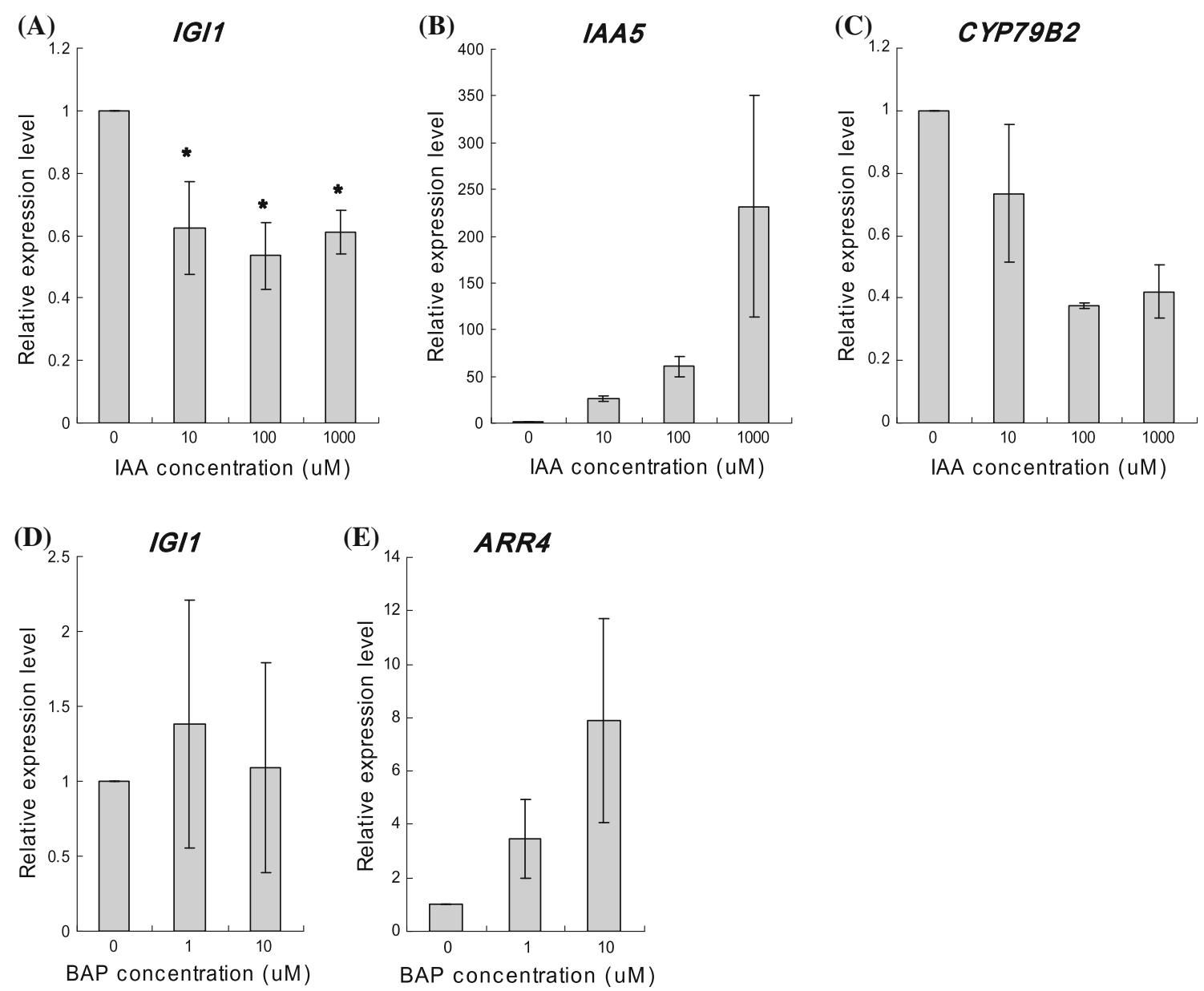

Fig. 5 Effect of auxin and cytokinin on IGII gene expression. Untreated 7 day old wild type seedlings were transferred to IAA and BAP treated medium and the seedlings were then used to test the hormone response within $3 \mathrm{~h}$ of treatment. There was no change in $I G I 1$ gene expression in response to BAP treatment (d); however, $I G I 1$ gene expression was down-regulated in response to exogenous

plants and the igil mutants (Supplemental Fig. 2). In the BAP response, the transcript levels of the IGII gene were similar to those of the wild type (Fig. 5d). Additionally, the transcript levels of the cytokinin response gene and BAP response showed that there is no relationship between IGI1 and cytokinin.

In igil mutants, the transcript levels of the auxin biosynthesis components, CYP79B2 and CYP79B3, increased; however, igil/IGII mutants showed the opposite axillary branching pattern. Based on these findings, we tested the transcript level of the genes enhanced by auxin treatment in the igil mutants. With the exception of PIN1, no variation in the transcript levels was observed in 10- and 20-day-old plants, which suggests that the negative feedback effect of the auxin response may have affected the overexpression effect of the $C Y P 79 B 2$ and $C Y P 79 B 3$ in igil mutants (Fig. 4). Moreover, the IGII gene was down-regulated by IAA treatment (Fig. 5a). These results indicate that
IAA treatment, regardless of the concentration (a). The IAA5, $C Y P 79 B 2$, and ARR4 genes were used to verify the accuracy of the experimental method (b, c, and e). The actin transcript levels were used for normalization. Error bars indicate the standard deviation. The work was repeated two times with same result. Asterisks indicate values significantly different from the $0 \mathrm{uM}(P<0.05)$

hormonal regulation by other than auxin and cytokinin components influenced axillary branching.

The MAX-dependent carotenoid hormone, strigolactone, moves up the plant from the root and prevents bud outgrowth (Bainbridge et al. 2005; Stirnberg et al. 2002, Gomez-Roldan et al. 2008; Umehara et al. 2008). Strigolactone works in the downstream of auxin in the regulation of bud outgrowth (Brewer et al. 2009; Waldie et al. 2010). Moreover, auxin has been shown to promote the expression of strigolactone biosynthesis genes, MAX3 and MAX4 (Hayward et al. 2009). It is believed that the increased transcript level of IGII when compared with the wild type plants influenced the MAX3 and MAX4 transcript levels that were observed in the present study (Fig. 6). Therefore, the lower transcript levels of the MAX3 and MAX4 in the igil mutants influenced the increased branching phenotypes. The lower transcript levels of the MAX3 and MAX4 could result in the altered transcript levels of the auxin 

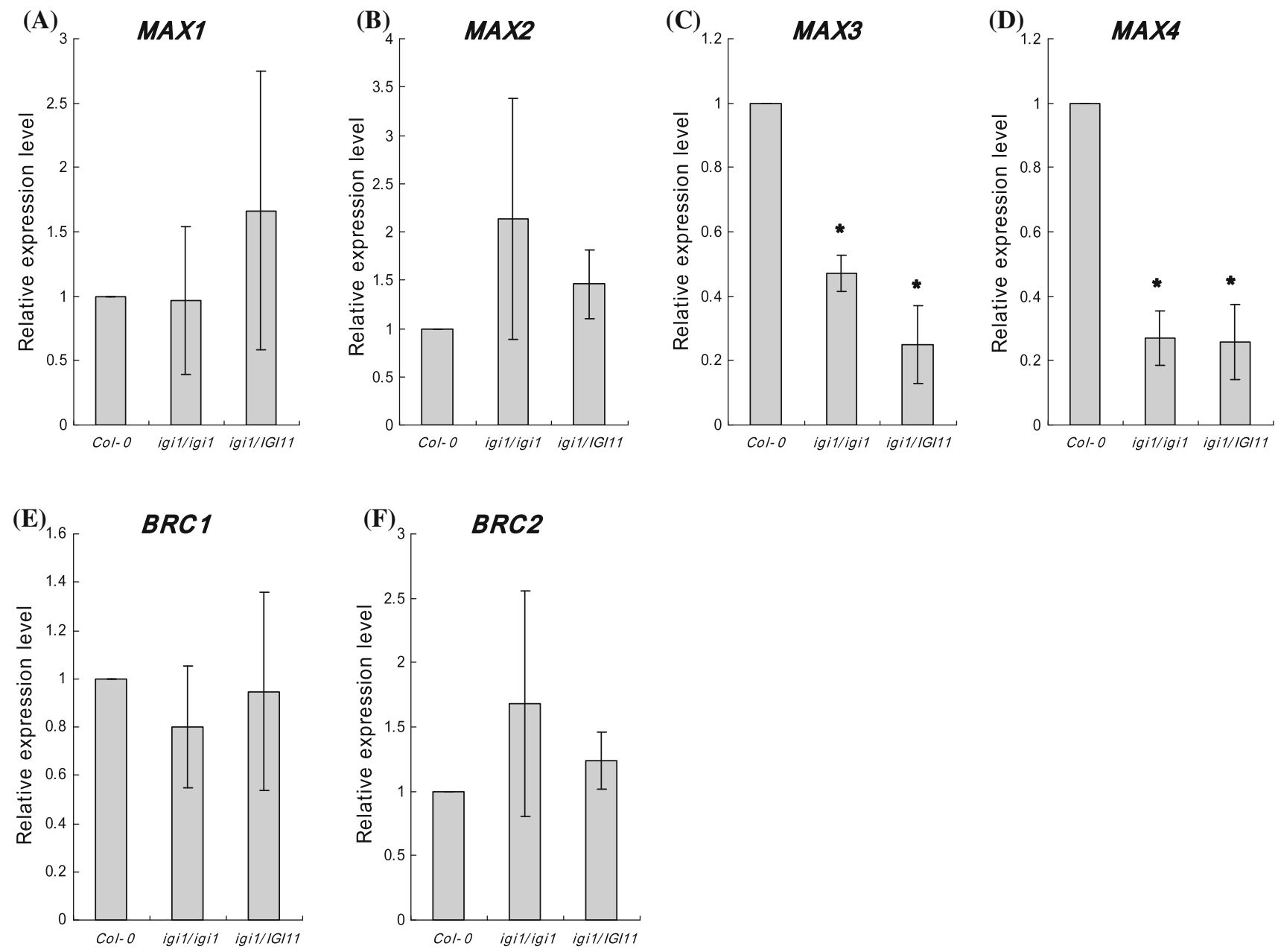

Fig. 6 Real-time PCR analysis related genes involved in branching. The graph shows the relative expression levels of branching control genes. MAX3 and MAX4 were down-regulated in igil mutant (c and d). $M A X 1, M A X 2, B R C 1$ and $B R C 2$ showed no detectable expression levels in igil mutants. The PCR reaction was performed using the

biosynthesis gene, CYP79B2 and CYP79B3 (Fig. 4). Actually, it was reported that increased auxin levels have been observed in rice strigolactone mutant (Arite et al. 2007). At $100 \mathrm{nmol} / \mathrm{L}$ concentration of auxin, PIN1-GFP expressed under PINI promoter increased but PINI, transmembrane component of the auxin efflux carrier (Gälweiler et al. 1998; Petrásek et al. 2006), transcript decreased at higher auxin concentrations (Vieten et al. 2005). The lower transcript level of PIN1 in igil mutants is expected to effect on the feedback of the branching phenotype (Fig. 4). However, PIN1:GFP fusion protein levels and PIN1p::GUS activity were elevated in the max mutants when compared to the wild type plants, suggesting that the MAX pathway acts to control the expression of the PIN transporters (Bennett et al. 2006; Ferguson and Beveridge 2009). Although the transcript levels of PIN1 were decreased in igil mutants, the result showed other

cDNA of a 25-day-old plant. The actin transcript levels were used for normalization. Error bars indicate the standard deviation. Results are the mean of at least three times. Asterisks indicate values significantly different from the wild type Col- $0(P<0.05)$

possibility of various pathways which controls the shoot branching related with PIN1 transporters.

The amino acid of IGI1 contains a proline rich domain in N-terminal region and kinase domain signature in the C-terminal region (Fig. 7). The proline rich region is present in the PERK protein family in Arabidopsis. The basic structural features of conserved sequence regions are consisted of proline-rich domain, transmembrane domain and kinase domain. Some of AtPERK members were identified as tissue-specific genes while others were more broadly expressed. In NASCArrays, strong expression was seen for AtPERK4, 5, 6, 7, 11 and 12 in flower buds. RNA gel blot analyses demonstrated that the majority of the AtPERK famly are expressed in buds (Nakhamchik et al. 2004). Our results also showed similar results with PERK family expression patterns, which were highly detected in flower buds by real time PCR and GUS staining (Fig. 3). 
Fig. 7 Predicted amino acid sequence of the IGI1. a Amino acid sequence of IGI1. Prolines are indicated by grey shading and the underlining indicated protein kinase signature. b Domain organization of the PERK1 and IGI1 (PERK12). The PERK1 and IGI1 possessed proline rich, transmembrane and kinase domain
(A)

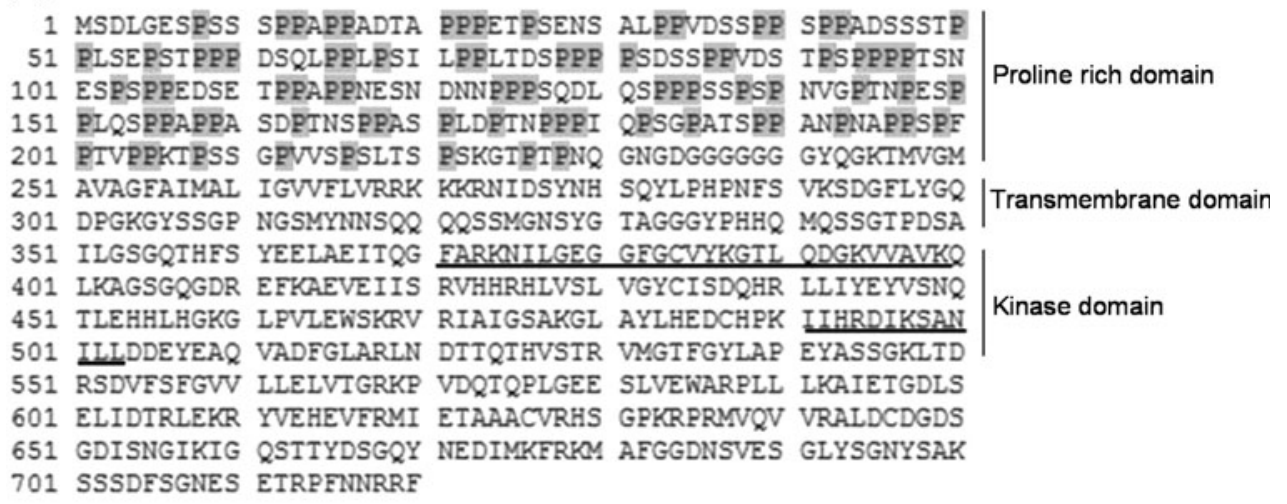

- Protein kinase region Proline

(B)

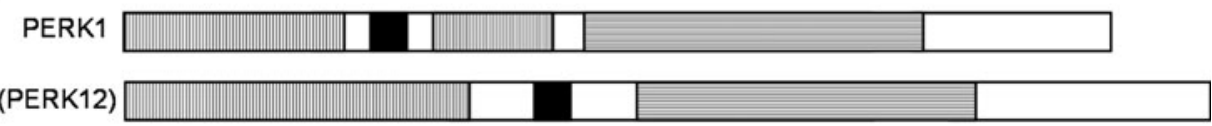

\begin{tabular}{|l|l|l|l|l|}
\hline IGI1(PERK12) & \\
\hline
\end{tabular}
These results indicate that IGI1 might be a receptor which was associated with flowering. The developmental phenotypes of heterozygous mutant become noticeable after transition from vegetative to reproductive phase. These results suggest that there may be a novel pathway of the axillary meristem development through IGI1, which was modulated by flowering a regulated pathway.

During the vegetative phase under long day conditions, the leaves of Arabidopsis are formed at the shoot tip, after which they expand. Vegetative meristems are converted into inflorescence meristems, floral meristems, etc. During the transition from vegetative growth to reproductive growth in Arabidopsis, the elongation growth of axillary buds at the rosette and cauline nodes is maintained and inflorescences including floral organs are formed in determinate or indeterminate forms. For example, the terminal flower in the terminal bud is formed via determinate inflorescence. However, the terminal bud continues growing and forming lateral flowers during indeterminate inflorescence. The formation of the flower is very important during plant development. Flowers may transduce a variety of signals into each organ during plant morphogenesis. In the present study, high levels of IGII expression were detected in the flower bud by real time PCR. Conversely, IGI1::GUS activity was detected only in the root hairs of plants in the vegetative phase and strongly in the anther of plants in the reproductive phase (Fig. 3). If each shoot tip was continuously decapitated, shoot branching should emerge at each axils (Shimizu-Sato and Mori 2001). This phenomenon has been called apical dominance. Shoot apical buds include floral meristems and sometimes flowers. The induction of apical dominance by factors related to auxin or other compounds can lead to branching patterns. In the present study, branching patterns were observed at the axils of rosette and cauline leaves in the igil/IGII mutant. Taken together, these results suggest that the pathway through IGI1 may be involved in the MAX pathway via auxin and delivers other signals to each axil. Furthermore, these results indicate that IGI1 is involved in the communication between axillary buds and the flowers involved in axillary bud development.

\section{Materials and methods}

Plant materials and growth conditions

Arabidopsis thaliana Columbia-0 (Col-0) was used as the wild type. Seeds were surface sterilized with $70 \%$ Ethanol containing $0.05 \%$ tritonX-100 and 95\% Ethanol. After plating on half strength Murashige and Skoog (MS) medium supplemented with $1 \%$ sucrose (1/2MS.1S), the samples were wrapped with aluminum foil and cold treated at $4^{\circ} \mathrm{C}$ for 3 days. After germination, the seeds were transferred to soil and grown in the growth room at $22^{\circ} \mathrm{C}$ under a 16 h: 8 h light: dark cycle.

\section{TAIL-PCR}

TAIL (Thermal Asymmetric Interlaced)-PCR (polymerase chain reaction) (Liu et al. 1995) was conducted using long primers specific for the T-DNA and short arbitrary primers 
specific for the genomic DNA (Supplemental Table 1). Three PCR reactions were conducted using the T-DNA primers-LB150, LB100, and LB50 and the AD primer pairs to produce a specific product of the genomic sequence flanking a T-DNA insertion. The last amplification band was eluted and subjected to sequencing. The T-DNA insertion sites of the transgenic lines were identified by a basic local alignment search tool (BLAST) search.

\section{Construction}

pMN20 vector including the four enhancers was used to recapitulate the igil phenotypes (Weigel et al. 2000). The IGIl gene was produced by PCR amplification. PCR reactions were conducted using the $50 \mathrm{KC} 1 \mathrm{~F}\left(5^{\prime}\right.$-AAC TGC AGA GGT ATC TGT TAC TTT CAC CTA- ${ }^{\prime}$ ) and 50KC1R (5'-TTC TGC AGG CCC ATC TAG ATT TCA CAT CAT- $3^{\prime}$ ) primers. The PstI restriction site was used to clone the IGII gene.

The pHANNIVAL vector was used for gene silencing (RNAi). The 300 base pairs (bp) of the IGIl gene coding region were amplified from Col-0 using primers that contained an added $K p n I$ site on the end of one product (sense strand) and the BamHI site on the end of the other product (anti-sense strand). The sequences of the PCR primers were as follows: for the sense strand amplification, forward (RIKpnI2F) 5'-CGG GTA CCA GAA TGT CTA ACA CAT GCA GC- $3^{\prime}$ and reverse (RIKpnI2R) $5^{\prime}$-CGG GTA CCT AGC GCC GGA ATA TGC ATC A- $3^{\prime}$; for the antisense strand, forward (RIBamHI2F) $5^{\prime}$-CGG GAT CCA GAA TGT CTA ACA CAT GCA GC- $3^{\prime}$ and reverse (RIBamHI2R) 5'-CGG GAT CCT AGC GCC GGA ATA TGC ATC A-3'. The products amplified using these primers were then digested with $K p n \mathrm{I}$ and BamHI restriction enzymes and directly cloned into the pHANNIVAL vector. An intron containing hairpin RNA construct was used to identify silencing of the targeting gene. The cloning region of the pHANNIVAL vector contains an intron that induces self complementarity between the sense and antisense targeting RNA strand (Wesley et al. 2001). The construct was then digested with the SacI and PstI restriction enzymes, after which the fragment was subcloned into the pUC18 multi cloning site of the binary vector, pCAMBIA1302.

We generated a construct, IGI1::GUS for analysis of the expression pattern of IGII gene. The predicted promoter region of the IGII gene was amplified from wild type genomic DNA by PCR using the following primers: KCPCF6, 5'-TCG GAT CCG GCG ACT CGC CTA AGT CTG ACA T-3' and KCPCR5, 5'-AGG GAT CCT ATA CTA AGA TCA CGT TAC TTG CC-3'. The PCR product was then digested with the BamHI restriction enzyme and directly cloned into pBI101.2 binary vector. The construct was introduced into the Col-0 plant. All constructs were confirmed by PCR, enzyme digestion and sequencing (data not shown).

\section{Plant transformation}

All cloned vectors were introduced into Agrobacterium tumefaciens (A. tumefaciens) strain GV3101 using the freeze and thaw method. Briefly, competent $A$. tumefaciens cells were mixed with approximately $1 \mu \mathrm{g}$ of DNA in a micro-tube. The mixture was then frozen with liquid nitrogen $\left(\mathrm{LN}_{2}\right)$ for $2 \mathrm{~min}$ and was then incubated for $5 \mathrm{~min}$ at $37^{\circ} \mathrm{C}$. The freezing-thawing step was then repeated one more time, after which the tube was incubated on ice for $30 \mathrm{~min}$. Next, the cell mixture was spread on YEP plates (10 g/l Bacto-peptone, $10 \mathrm{~g} / \mathrm{l}$ Bacto-yeast extract, and $5 \mathrm{~g} / \mathrm{l}$ $\mathrm{NaCl}$ ) containing antibiotics using a bent glass rod. Colonies were confirmed by digestion and PCR. Agrobacteriummediated transformation was then conducted by the dipping transformation protocol. Briefly, Agrobacterium was grown to the mid-log phase in YEP medium, pelleted and then resuspended in infiltration medium (1/2 MS salt, Gamborg's vitamin $112 \mathrm{mg} / \mathrm{l}$ (Duchefa, G0415), and $0.44 \mu \mathrm{M}$ benzylamino purine). The plants were then inverted in the infiltration media for $15 \mathrm{~min}$ and were then immediately loosely covered with plastic wrap to maintain humidity. The plastic wrap was removed after 1 day, after which the soil was allowed to dry for 1 week and then watered. T1 seeds were then selected on 1/2MS medium containing antibiotics to obtained transformed plants, while $\mathrm{T} 2$ seeds were selected to obtain single copy lines and T3 seeds were selected to distinguish homozygous and heterozygous lines.

RNA preparation and cDNA synthesis

Total RNA was isolated from plant tissues using Trizol reagent (Life Technologies). Briefly, $100 \mathrm{mg}$ of the plant tissue were homogenized by freezing in liquid nitrogen and then grinding to a very fine powder. $1 \mathrm{ml}$ of TRIzol reagent was added to the homogenized tissue samples, which were then mixed and incubated at room temperature for $10 \mathrm{~min}$. Subsequently, $0.2 \mathrm{ml}$ of chloroform was added to the samples, which were then incubated for $3 \mathrm{~min}$ at room temperature. The samples were then centrifuged at 13,000 rpm for $15 \mathrm{~min}$ at $4^{\circ} \mathrm{C}$, after which the colorless upper aqueous phase was transferred to a new tube. Next, $0.5 \mathrm{ml}$ of isopropyl alcohol was added to the samples, which were then removed and the pellet was washed with $70 \%$ ethanol and dried. cDNA was then synthesized using superscript II reversetranscriptase (Invitrogen). Next, $4 \mu \mathrm{l}$ (about $2 \mu \mathrm{g}$ ) of total RNA and $1 \mu \mathrm{l}$ of the oligo dT $(500 \mu \mathrm{g} / \mathrm{ml})$ were mixed in the reaction tube and then heated at $65^{\circ} \mathrm{C}$ for $10 \mathrm{~min}$. The enzyme was then added into the tube and incubated at $42^{\circ} \mathrm{C}$ 
for $50 \mathrm{~min}$. Finally, the reaction tube was incubated at $70^{\circ} \mathrm{C}$ for $15 \mathrm{~min}$ to inactivate the sample.

\section{Quantitative real-time PCR}

Quantitative real-time PCR (Q-PCR) was conducted using cDNA from mutant and wild type plants. For IGI1 gene amplification, the forward primer (EPKF) 5'-AGG CGA TTG AAG ATC TTG AGA CGG AGG A-3' and the reverse primer (EPKR) 5'-ATG TCA GAC TTA GGC GAG TCG CCG AGT TCT-3' were used. Specifically, the QuantiTect SYBR Green PCR Kit (QIAGEN) containing SYBR Green PCR Master Mix ROX as a passive reference dye, HotStarTaq DNA Polymerase and dNTP Mix, 5 pmol of both primers (forward and reverse), $1 \mu \mathrm{l}$ of cDNA and RNase-free water were combined in a reaction tube. For the IGII gene, PCR was conducted by subjecting the samples to initial denaturation at $95^{\circ} \mathrm{C}$ for $15 \mathrm{~min}$ followed by 40 cycles of $95^{\circ} \mathrm{C}$ for $20 \mathrm{~s}, 55^{\circ} \mathrm{C} 20 \mathrm{~s}, 72^{\circ} \mathrm{C}$ for $40 \mathrm{~s}$ and a final extension at $72^{\circ} \mathrm{C}$ for 5 min using a real-time DNA detection system (Corbett co., RG-3000, Australia). The results were analyzed using RG-3000 software and a Delta Delta CT method (Livak and Schmittgen 2001). The primer pairs for multiple branching control genes, cytokinin response genes, and auxin biosynthesis genes are described in Supplemental Table 2. Actin primer set was used for normalization of Q-PCR and consisted of a forward, 5'-GGC GAT GAA GCT CAA TCC AAA CG-3', and a reverse primer, 5'-TCA CGA CCA GCA AGA TCA AGA CG-3'.

\section{Histochemical analysis}

4-Methylumbelliferyl-beta-D-glucuronide (MUG) assay was conducted to evaluate the GUS activity. Briefly, samples were ground with $150 \mu \mathrm{l}$ of extraction buffer $(50 \mathrm{mM}$ sodium phosphate buffer ( $\mathrm{pH} 7.0$ ), $10 \mathrm{mM}$ EDTA, $0.1 \%$ triton X-100, $0.1 \%$ sarcosyl, $10 \mathrm{mM} \beta$-mercaptoetahnol). The samples were then centrifuged at 13,000 rpm for $10 \mathrm{~min}$ at $4^{\circ} \mathrm{C}$, after which the upper aqueous phase was transferred to a new tube. Next, the protein concentration was measured with Bradford reagent using $25 \mu \mathrm{g}$ of sample. After the protein concentration was determined, $8 \mu$ l of MUG stock solution were added to the sample and the mixture was then incubated for $1 \mathrm{~h}$ at $37^{\circ} \mathrm{C}$. After $1 \mathrm{~h}, 40 \mu \mathrm{l}$ of the sample mixture and $160 \mu \mathrm{l}$ of $0.2 \mathrm{M} \mathrm{Na}_{2} \mathrm{CO}_{3}$ were mixed to stop the reaction and the activity was determined based on the absorbance at $420 \mathrm{~nm}$. Histochemical analysis using GUS staining was conducted by incubating the sample tissue in GUS staining buffer containing $2 \mathrm{mM}$ cyclohexylammonium salt (Duchefa), $100 \mathrm{mM}$ sodium phosphate buffer $(\mathrm{pH}$ 7.0), $10 \mathrm{mM}$ EDTA, $0.5 \mathrm{mM}$ potassium ferrocyanide, $0.5 \mathrm{mM}$ potassium ferricyanide, and $0.1 \%$ triton $\mathrm{X}-100$ (volume in volume, v/v) for $16 \mathrm{hs}$. The samples were then destained with $70 \%(\mathrm{v} / \mathrm{v})$ ethanol.

Acknowledgments This research was supported by Basic Science Research Program through the National Research Foundation of Korea (NRF) funded by the Ministry of Education, Science and Technology (NRF-2008-1-314-C00350).

Open Access This article is distributed under the terms of the Creative Commons Attribution Noncommercial License which permits any noncommercial use, distribution, and reproduction in any medium, provided the original author(s) and source are credited.

\section{References}

Aguilar-Martínez JA, Poza-Carrión C, Cubas P (2007) Arabidopsis BRANCHED1 acts as an integrator of branching signals within axillary buds. Plant Cell 19:458-472

Arite T, Iwata H, Ohshima K, Maekawa M, Nakajima M, Kojima M, Sakakibara H, Kyozuka J (2007) DWARF10, an RMS1/MAX4/ DAD1 ortholog, controls lateral bud outgrowth in rice. Plant $\mathrm{J}$ 51:1019-1029

Bainbridge K, Sorefan K, Ward S, Leyser O (2005) Hormonally controlled expression of the Arabidopsis MAX4 shoot branching regulatory gene. Plant J 44:569-580

Bangerth F (1994) Response of cytokinin concentration in the xylem exudate of bean (Phaseolus vulgaris L.) plants to decapitation and auxin treatment, and relationship to apical dominance. Planta 194:439-442

Bennett T, Sieberer T, Willett B, Booker J, Luschnig C, Leyser O (2006) The Arabidopsis MAX pathway controls shoot branching by regulating auxin transport. Curr Biol 16:553-563

Booker J, Auldridge M, Wills S, McCarty D, Klee H, Leyser O (2004) MAX3/CCD7 is a carotenoid cleavage dioxygenase required for the synthesis of a novel plant signaling molecule. Curr Biol 27(14):1232-1238

Booker J, Sieberer T, Wright W, Williamson L, Willett B, Stirnberg P, Turnbull C, Srinivasan M, Goddard P, Leyser O (2005) MAX1 encodes a cytochrome P450 family member that acts downstream of MAX3/4 to produce a carotenoid-derived branchinhibiting hormone. Dev Cell 8:443-449

Brewer PB, Dun EA, Ferguson BJ, Rameau C, Beveridge CA (2009) Strigolactone acts downstream of auxin to regulate bud outgrowth in pea and Arabidopsis. Plant Physiol 150(1):482-493

Cline MG (1997) Concepts and terminology of apical dominance. Am J Bot 84:1064-1069

Dun EA, Ferguson BJ, Beveridge CA (2006) Apical dominance and shoot branching. Divergent opinions or divergent mechanisms? Plant Physiol 142:812-819

Ferguson BJ, Beveridge CA (2009) Roles for auxin, cytokinin, and strigolactone in regulating shoot branching. Plant Physiol 149:1929-1944

Gälweiler L, Guan C, Müller A, Wisman E, Mendgen K, Yephremov A, Palme K (1998) Regulation of Polar Auxin Transport by AtPIN1 in arabidopsis vascular tissue. Science 282:2226-2230

Gomez-Roldan V, Fermas S, Brewer PB, Puech-Pagès V, Dun EA, Pillot JP, Letisse F, Matusova R, Danoun S, Portais JC, Bouwmeester $\mathrm{H}$, Bécard G, Beveridge CA, Rameau C, Rochange SF (2008) Strigolactone inhibition of shoot branching. Nature 455:189-194

Hayward A, Stirnberg P, Beveridge C, Leyser O (2009) Interactions between auxin and strigolactone in shoot branching control. Plant Physiol 151:400-412 
Higuchi M, Pischke MS, Mähönen AP, Miyawaki K, Hashimoto Y, Seki M, Kobayashi M, Shinozaki K, Kato T, Tabata S, Helariutta Y, Sussman MR, Kakimoto T (2004) In planta functions of the Arabidopsis cytokinin receptor family. Proc Natl Acad Sci 101:8821-8826

Li CJ, Bangerth F (1999) Autoinhibition of indoleacetic acid transport in the shoots of two-branched pea (Pisum sativum) plants and its relationship to correlative dominance. Physiol Plant 106:415420

Li CJ, Guevara E, Herrera J, Bangerth F (1995) Effect of apex excision and replacement by 1-naphthylacetic acid on cytokinin concentration and apical dominance in pea plants. Physiol Plant 94:465-469

Lincoln C, Britton JH, Estelle M (1990) Growth and development of the axr1 mutants of Arabidopsis. Plant Cell 2:1071-1080

Liu YG, Mitsukawa N, Oosumi T, Whittier RF (1995) Efficient isolation and mapping of Arabidopsis thaliana T-DNA insert junctions by thermal asymmetric intderlaced PCR. Plant J 8: $457-463$

Livak KJ, Schmittgen TD (2001) Analysis of relative gene expression data using real-time quantitative PCR and the 2(-Delta Delta $\mathrm{C}(\mathrm{T})$ ). Methods 25:402-408

Medford JI, Horgan R, El-Sawi Z, Klee HJ (1989) Alterations of endogenous cytokinins in transgenic plants using a chimeric isopentenyl transferase gene. Plant Cell 1:403-413

Morris DA (1977) Transport of exogenous auxin in two-branched dwarf pea seedlings (Pisum sativum L.). Planta 136:91-96

Morris SE, Cox MCH, Ross JJ, Krisantini S, Beveridge CA (2005) Auxin dynamics after decapitation are not correlated with the initial growth of axillary buds. Plant Physiol 138:1665-1672

Nakhamchik A, Zhao Z, Provart NJ, Shiu SH, Keatley SK, Cameron RK, Goring DR (2004) A comprehensive expression analysis of the Arabidopsis proline-rich extensin-like receptor kinase gene family using bioinformatic and experimental approaches. Plant Cell Physiol 45(12):1875-1881

Okushima Y, Overvoorde PJ, Arima K, Alonso JM, Chan A, Chang C, Ecker JR, Hughes B, Lui A, Nguyen D, Onodera C, Quach H, Smith A, Yu G, Theologis A (2005) Functional genomic analysis of the AUXIN RESPONSE FACTOR gene family members in Arabidopsis thaliana: unique and overlapping functions of ARF7 and ARF19. Plant Cell 17(2):444-463

Petrásek J, Mravec J, Bouchard R, Blakeslee JJ, Abas M, Seifertová D, Wisniewska J, Tadele Z, Kubes M, Covanová M, Dhonukshe P, Skupa P, Benková E, Perry L, Krecek P, Lee OR, Fink GR, Geisler M, Murphy AS, Luschnig C, Zazímalová E, Friml J (2006) PIN proteins perform a rate-limiting function in cellular auxin efflux. Science 312:914-918

Sachs T, Thimann KV (1967) The role of auxins and cytokinins in the release of buds from dominance. Am J Bot 54:136-144

Schachtschabel D, Boland W (2009) Strigolactones: the first members of a new family of "shoot branching hormones" in plants? Chembiochem 10:221-223

Sergeant MJ, Li JJ, Fox C, Brookbank N, Rea D, Bugg TD, Thompson AJ (2009) Selective inhibition of carotenoid cleavage dioxygenases: phenotypic effects on shoot branching. J Biol Chem 284:5257-5264
Shimizu-Sato S, Mori H (2001) Control of outgrowth and dormancy in axillary buds. Plant Physiol 127:1405-1413

Snowden KC, Simkin AJ, Janssen BJ, Templeton KR, Loucas HM, Simons JL, Karunairetnam S, Gleave AP, Clark DG, Klee H (2005) The decreased apical dominance1/Petunia hybrida CAROTENOID CLEAVAGE DIOXY-GENASE8 gene affects branch production and plays a role in leaf senescence, root growth and flower development. Plant Cell 17:746-759

Sorefan K, Booker J, Haurogné K, Goussot M, Bainbridge K, Foo E, Chatfield S, Ward S, Beveridge C, Rameau C, Leyser O (2003) MAX4 and RMS1 are orthologous dioxygenase-like genes that regulate shoot branching in Arabidopsis and pea. Genes Dev 17:1469-1474

Stafstrom JP, Sussex IM (1992) Expression of a ribosomal protein gene in axillary buds of pea seedlings. Plant Physiol 100:14941502

Stirnberg P, Chatfield SP, Leyser HM (1999) AXR1 acts after lateral bud formation to inhibit lateral bud growth in Arabidopsis. Plant Physiol 121:839-847

Stirnberg P, van De Sande K, Leyser HM (2002) MAX1 and MAX2 control shoot lateral branching in Arabidopsis. Development 129:1131-1141

Tantikanjana T, Yong JW, Letham DS, Griffith M, Hussain M, Ljung K, Sandberg G, Sundaresan V (2001) Control of axillary bud initiation and shoot architecture in Arabidopsis through the SUPERSHOOT gene. Genes Dev 15:1577-1588

Thimann KV, Skoog F (1933) Studies on the growth hormone of plants. III. The inhibition action of the growth substance on bud development. Proc Natl Acad Sci 19:714-716

Umehara M, Hanada A, Yoshida S, Akiyama K, Arite T, TakedaKamiya N, Magome H, Kamiya Y, Shirasu K, Yoneyama K, Kyozuka J, Yamaguchi S (2008) Inhibition of shoot branching by new terpenoid plant hormones. Nature 455:195-200

Vieten A, Vanneste S, Wisniewska J, Benková E, Benjamins R, Beeckman T, Luschnig C, Friml J (2005) Functional redundancy of PIN proteins is accompanied by auxin-dependent crossregulation of PIN expression. Development 132:4521-4531

Waldie T, Hayward A, Beveridge CA (2010) Axillary bud outgrowth in herbaceous shoots: how do strigolactones fit into the picture? Plant Mol Biol 73:27-36

Ward SP, Leyser O (2004) Shoot branching. Curr Opin Plant Biol 7:73-78

Weigel D, Ahn JH, Blázquez MA, Borevitz JO, Christensen SK, Fankhauser C, Ferrándiz C, Kardailsky I, Malancharuvil EJ, Neff MM, Nguyen JT, Sato S, Wang ZY, Xia Y, Dixon RA, Harrison MJ, Lamb CJ, Yanofsky MF, Chory J (2000) Activation tagging in Arabidopsis. Plant Physiol 122:1003-1013

Wesley SV, Helliwell CA, Smith NA, Wang MB, Rouse DT, Liu Q, Gooding PS, Singh SP, Abbott D, Stoutjesdijk PA, Robinson SP, Gleave AP, Green AG, Waterhouse PM (2001) Construct design for efficient, effective and high-throughput gene silencing in plants. Plant J 27:581-590

Zhao Y, Hull AK, Gupta NR, Goss KA, Alonso J, Ecker JR, Normanly J, Chory J, Celenza JL (2002) Trp-dependent auxin biosynthesis in Arabidopsis: involvement of cytochrome P450 s CYP79B2 and CYP79B3. Genes Dev 16:3100-3112 